\title{
A proibição do incesto \\ em Lévi-Strauss e Freud: algumas aproximações
}

DOI

http://dx.doi.org/10.11606/ 2179-0892.ra.2018.145521

\section{Janaina Namba}

- Universidade Federal de São Carlos / São Carlos, SP, Brasil

$\boldsymbol{\nabla}$ janaina.namba@yahoo.com.br

RESUMO

Em As estruturas elementares do parentesco (1949), Lévi-Strauss se refere à proibição do incesto como uma regra encontrada em todos os povos e em todos os tempos, ou seja, uma regra universal que marca a passagem da natureza para a cultura. Já Freud, em Totem e tabu (1913), descreve essa regra como uma consequência de um ato parricida, que daria origem à cultura. A proposta deste texto é refletir sobre algumas aproximações que podem ser feitas entre a antropologia estrutural de Lévi-Strauss e a psicanálise freudiana no que diz respeito à proibição do incesto.

\section{PALAVRAS-ChAVE}

Claude Lévi-Strauss, Sigmund Freud, interdição do incesto, complexo de Édipo, mito 
Para o etnólogo Lévi-Strauss, em As estruturas elementares do parentesco (1949), a proibição do incesto vem a ser uma regra universal, válida para todos os tempos que marca a passagem da natureza para a cultura. Nesse mesmo livro encontramos várias críticas feitas a Freud, especialmente ao que se refere a teoria psicanalítica da cultura, isto é, ao que a psicanálise freudiana considera como a origem da cultura.

Já no capítulo VII "A ilusão arcaica”, temos um bom exemplo dessa crítica veemente. Primeiramente o etnólogo coloca como problemática e inviável a analogia entre o pensamento primitivo e o pensamento da criança, bem como rejeita a afirmação de que haja uma herança filogenética da cultura. Tais críticas se dirigem mais diretamente ao famoso livro de 1913, Totem e tabu, no qual Freud diz abertamente que tenta "aplicar pontos de vista e resultados da psicanálise a problemas não esclarecidos da etnopsicologia" (Freud, 1913: 31). Além disso sugere que os quatro ensaios apresentados no livro possam promover "uma mediação entre etnólogos, linguistas, folcloristas, etc. de um lado e psicanalistas de outro", para que sejam produzidos encontros "mais frequentes" e "menos improdutivos para a pesquisa" entre esses grupos (Freud, 1913: 32).

Lévi-Strauss, por sua vez, argumenta que essa mediação com a psicanálise freudiana não seja possível, já que particularmente em Totem e tabu, seu autor venha incorrer em hipóteses contraditórias:

Admitamos de uma vez por todas que uma criança não é um adulto; mas permaneçamos fiéis a esta afirmação e não nos adiantemos, de maneira insidiosa, como o fazem os psicólogos e psiquiatras, em desmenti-la insinuando que o pensamento da criança normal se assemel ha ao do adul to primitivo, ou ao do adulto doente mental (Lévi-Strauss (1949) 1967: 108). ${ }^{7}$

1 As traduções dos textos de Lévi-Strauss são de minha autoria.

Ou seja, uma vez feita a distinção entre a criança e o adulto, essa deve ser respeitada, pois são extensas as implicações sociais e individuais do ponto de vista da antropologia estrutural. Isso por que

os esquemas mentais do adulto divergem segundo a cultura e a época a que cada um pertence, ainda que esses sejam elaborados a partir de um fundo universal, infinitamente mais rico que aquele disposto em cada sociedade particularmente, e, apesar de cada criança trazer consigo, ao nascer e de uma forma embrionária, a soma total das possibilidades que cada cultura e de cada período da história, escoIherão apenas alguns para reter e desenvolver (Lévi-Strauss, (1949) 1967: 108).

Isto é, esses esquemas passam por um processo de especialização e especificação de acordo com cada cultura relativamente a um determinado tempo. 
De fato, ao longo de sua obra, Freud pega emprestado da antropologia e da psicologia de sua época a ideia de que tenha havido uma infância da humanidade primordial, bem como, a compara com o indivíduo neurótico e com a criança. Melhor dizendo, compara essa infância da humanidade com as fases em que é evidente, como no caso do neurótico, uma estagnação do desenvolvimento psíquico-sexual e, no caso da criança, seu desenvolvimento propriamente dito. Para a psicanálise freudiana, a comparação é fundamental, já que em 1912-13, Freud se ocupava diretamente de assuntos da cultura, assim como alguns de seus pares, com quem rivalizava. Ademais, para além de formular uma teoria da cultura, ele busca na humanidade algo que lhe desse respaldo e the explicasse o funcionamento psíquico, tendo como mecanismo central das neuroses, as interdições ao incesto e ao parricídio (o complexo de Édipo), uma vez que isso significava embasar cientificamente uma teoria psíquica do indivíduo.

De acordo com Nayrou, "a interdição ocupará, ao longo da obra freudiana, diferentes acepções de uma mesma lógica, a saber, sempre aquela de uma proibição fundamental" (Nayrou in Durieux, Nayrou e Parat 2006: 71). ${ }^{2}$ Essa proibição, inicialmente externa, é responsável, na infância, pela formação de uma instância psíquica ideal, o ideal de ego ou superego. Essa instância internalizada, que é responsável pela proibição, nomeada como instância herdeira do complexo de Édipo, depende de uma unidade pulsional, do investimento libidinal e de identificações com as figuras parentais:

Essa instância pós-edipiana vem se agregar a outros modos menos elaborados de interdições que perduraram; ela incide sobre as proibições mais arcaicas que as interdições morais e sociais claramente enunciadas, e que se encontram situadas num registro de marcas simbólicas precocemente transmitidas ou seja, nas relações entre a mãe-bebê (Nayrou in Durieux, Nayrou e Parat 2006: 72).

No entanto, temos em comum que tanto para Lévi-Strauss, em As estruturas elementares... quanto para Freud, em Totem e tabu, a interdição do incesto é considerada como um marco fundador da cultura. Dessa maneira nosso texto se propõe a comparar as abordagens desse fato universal por essas duas disciplinas, como um fato que delineia a oposição entre natureza e cultura.

De acordo com Keck, "a análise da proibição do incesto é sem dúvida a passagem mais célebre da antropologia de Lévi-Strauss" permitindo-lhe assim tomá-la como um dos pilares fundadores do "estudo das estruturas universais do espírito humano" (2011: 84). ${ }^{3}$ Anteriormente muitos antropólogos e sociólogos já haviam se debruçado sobre o fenômeno da interdição do incesto, mas o que o torna particularmente problemático é justamente o fato de saber se é uma regra pertencente à natureza ou à cultura: "De fato, se a proibição do incesto é reconhecida
2 A tradução desse texto em francês foi realizada pela autora.

3 A tradução desse texto foi realizada pela autora. 
universalmente, portanto devemos explicar essa universalidade pela natureza (uma necessidade biológica) ou pela cultura (coação social)?” (Keck, 2011: 86).

De acordo com Lévi-Strauss, não há o menor equívoco ao dizermos que a proibição do incesto reúne "as duas características em que podemos reconhecer atributos contraditórios de duas ordens exclusivas: ela constitui uma regra, mas uma regra dentre todas as regras sociais, que possui ao mesmo tempo uma característica de universalidade" (Lévi-Strauss, 1967:10). Ou seja, se é indiscutível que a interdição constitui uma regra, resta saber porque ela é universal. Quanto a isso tem-se que em todos os grupos sociais sempre há alguma categoria de pessoas cujo casamento é proibido. Nas palavras de Lévi-Strauss, "a proibição do incesto, por sua vez, possui tanto a universalidade das tendências e dos instintos quanto a característica coercitiva das instituições". Ela constitui uma regra que não conhece limites históricos ou geográficos, é "coextensiva no tempo e no espaço à espécie biológica", e se opõe ao que seriam as ações naturais, através de características próprias (Lévi-Strauss, (1949) 1967: 12).

Em Totem e tabu, Freud dedicou um capítulo para tratar do horror ao incesto, baseando-se nos dados obtidos pela antropologia do final do século XIX e início do século XX, de autores como Frazer, Tylor, Robertson Smith, Durkheim, Westermarck e outros. A partir de uma breve descrição de alguns povos australianos, que a esses antropólogos e a Freud pareciam muito diferentes de seus povos vizinhos como malaios, polinésios e melanésios, conjecturava-se que de fato esses povos australianos estariam muito distantes em termos religiosos, míticos, ou mesmo em seus hábitos, costumes, alimentação e organização social. Apesar de tudo parecer muito diferente, aos estudiosos, eles observaram que havia para todos eles "um enorme cuidado e uma penosa severidade" com a meta de impedir o estabelecimento de relações sexuais incestuosas, a partir do que conclui que "toda organização social parece servir a tal propósito ou estar ligada a tal realização" (Freud, 1913: 8). Ou seja, no que diz respeito à interdição do incesto há uma preocupação particular, mesmo dentre os povos considerados os mais selvagens e com costumes os mais diversos.

Freud argumenta nesse texto, assim como depois ressaltará Frazer em As origens da família e do clã (1922), que uma proibição como esta, na forma de lei ou de um tabu (no caso freudiano), só é necessária porque há uma grande propensão ao incesto. Em outras palavras, é necessário que haja uma coação exterior para que essa tendência não se realize. De uma maneira similar, Lévi-Strauss identifica essa ideia em Bergson, que também relaciona o totemismo com exogamia, como Frazer e Freud, no entanto, como um mecanismo instintivo que viria a previnir uniões biologicamente nocivas entre parentes próximos. Ora, se uma propensão biológica e, portanto, instintiva, como essa existisse dessa maneira, não haveria a necessidade de recorrer a uma determinação proibitiva por uma 
via institucional (Lévi-Strauss 1962b: 139). O que acaba por afastar os autores quanto à explicação sobre a interdição do incesto.

Em Totem e Tabu, Freud propõe abordar pelo viés da psicanálise problemas etnopsicológicos, mas, principalmente, analisar e compilar o sentido originário do totemismo, "desde seus traços infantis", dados os indícios desse que afloram no desenvolvimento de crianças na atualidade (Freud, 1913: 8) ${ }^{4}$. A maneira como empreende essa tarefa é a montagem de uma conjectura com bases históricas e científicas em torno do enigma do horror ao incesto: "Ainda tenho de mencionar uma tentativa para explicar a origem do horror ao incesto que é de um tipo inteiramente diferente [...]. Poderíamos caracterizá-la como uma dedução histórica" (Freud, 1913: 187).

Freud parte de uma hipótese de Darwin sobre a situação primordial dos seres humanos, que viveriam como os símios superiores, em pequenas hordas, as quais eram controladas por um "macho mais velho e mais forte e que impedia a promiscuidade sexual” (Freud, 1913: 188). Mas ressalta que essa condição humana é uma hipótese, e, que uma liga dos varões, assassinos do pai ciumento que tomava para si todas as mulheres e expulsava seus filhos, provavelmente nunca existiu . No entanto, aponta para algumas observações feitas em "organizações mais primitivas" (Freud, 1913: 207), isto é, para a composição de algumas tribos, organizadas a partir de uma liga de varões com direitos iguais e submetida às restrições totêmicas. Dessa maneira, propõe uma ligação entre o totemismo e o surgimento da sociedade:

Um dia os irmãos expulsos se aliaram, mataram e devoraram o pai, pondo um fim à horda paterna. Unidos, ousaram fazer e levar a cabo o que individualmente lhes teria sido impossivel. [...] O pai primordial violento era certamente o arquétipo invejado e temido de cada um dos membros do bando dos irmãos. $E$ no ato de lhe devorar, consumavam a identificação que tinham com ele, cada um se apropriava de parte da sua força. O banquete totêmico seria então a primeira festa da humanidade, seria a repetição e celebração daquela façanha memorável e criminosa que fora o início de tantas coisas: as organizações sociais, as limitações éticas e a religião (Freud, 1913: 208).

Para Lévi-Strauss, essa hipótese freudiana incorre num grande erro, pois com ela, Freud em vez de assumir uma postura científica sólida e madura, acaba por se confundir com o próprio neurótico. O psicanalista constrói uma teoria com base em outras teorias, há muito ultrapassadas, bem como delimita histórica e cientificamente um fato fictício, sem que esse possa ser comprovado. Segundo o etnólogo,
4 Tradução dessa edição de Totem e tabu foi realizada por Renato Zwick. 
essas audácias relativas a Totem e tabu, cujas hesitações que Ihes acompanham são reveladoras: elas mostram uma ciência social como a psicanálise - pois esta é uma - ainda oscilante entre uma tradição histórica, que busca num passado distante a razão de ser de uma situação atual, e uma atitude mais moderna e cientificamente mais sólida, que espera da análise do presente, o conhecimento de seu futuro e de seu passado. (...) Ao aprofundar a estrutura dos conflitos, cujo doente é o tea tro, para refazer a história e alcançar assim a situação inicial em torno da qual todos os desenvolvimentos subsequentes estão organizados; ele segue um caminho contrário ao da teoria que apresenta em Totem e tabu. Num caso vai da experiência aos mitos e dos mitos à estrutura; no outro inventa um mito para explicar os fatos; ou seja, procede como o doente no lugar de interpretá-lo (Lévi-Strauss, (1949)1967: 564).

Freud diz com todas as letras que uma tribo como a descrita em Totem e tabu nunca existiu, mas há de fato, uma insistência de que haja uma comprovação histórica dos efeitos da horda. A comprovação desse fato, de acordo com o fundador da psicanálise, seria dada a partir do drama da culpa vivida pelo neurótico obsessivo, o que indicaria uma culpa de algo vivido, das experiências infantis, mesmo que tenham sido vividas através das fantasias (primordiais, como veremos a seguir). Segundo Freud, nas últimas páginas de Totem e tabu:

Não é correto que os neuróticos obsessivos que hoje se encontram sob a pressão de uma hipermoral apenas se defendam da realidade psíquica das tentaçõese se punam devido a impulsos [Impulse] meramente sentidos. Também há uma parcela histórica mesclada aí; (...) (Freud, 1913: 230).

Em outras palavras, Freud nos apresenta, pela via da neurose, uma possível herança filogenética deduzida a partir de analogias entre as ações dos primitivos e os sintomas neuróticos. Esses sintomas carregariam não apenas o impulso da realidade psíquica, mas também reforços de uma herança da infância individual que repete, em alguma medida, ações primitivas. Para os primitivos, "a realidade psíquica, inicialmente coincidia com a realidade factual; [eles] fizeram o que, segundo todos os testemunhos, tinham a intenção de fazer" (Freud, (1913) 2013: 231).

\section{TRANSMISSÃO E HISTÓRIA}

Por um lado Lévi-Strauss desconsidera a possibilidade de que haja alguma transmissão filogenética, ou que a cultura possa ser recapitulada pelo indivíduo no presente. Para o etnólogo as estruturas mentais infantis, anteriormente mencionadas, são esboços, estruturas vazias que ficam restritas a impor regras e, por sua 
vez, também dependem da cultura para serem selecionadas, pois só podem se erigir como um esquema mental do adulto através da sedimentação da própria cultura que delimita e restringe o esquema mental infantil. Por outro, o autor toma a hipótese do parricídio do pai primordial da horda, que vem a instaurar o horror ao incesto e a exogamia como um mito. Mesmo que esse horror possa ser transmitido, considera que deva ser abordado em seus diversos códigos, dos quais só se apreende versões. Em O totemismo hoje, Lévi-Strauss nos diz que

as coações sociais positivas e negativas, não são explicadas quanto à sua origem, nem quanto à sua persistência, pelo efeito das pulsões ou das emoções que reaparecem com as mesmas características ao longo dos séculos e dos milênios em diferentes indivíduos (...). Os homens não agem, enquanto membros do grupo, conforme o que cada um sente como indivíduo: cada homem sente à maneira que Iheé permitido ou prescrito conduzir (Lévi-Strauss, 1962b: 104-105).

Mas como seria então a transmissão desse mito parricida e instaurador da interdição ao incesto para a psicanálise? A equação psicanalítica apresentada a seguir proposta por Freud mostra que três séries se complementam. A partir dessa equação e possível dizer que a patologia, além de depender de causas constitucionais, também está relacionada às vivências acidentais, sejam elas infantis, sejam elas do adulto. Além disso, nessa equação as causas constitucionais determinam uma disposição pré-histórica, ou seja, que envolve não apenas a história individual, mas também uma história pregressa. Vejamos mais de perto:

Os elementos que compõem essa equação são as vivências acidentais da criança e do adulto, e as vivências pré-históricas ou ainda, a própria constituição sexual da criança. A etiologia da neurose se encontra na infância, em impressões que afetam a vida sexual da criança, de maneira mais precisa, localizadas nas fantasias de infância afloradas por vivências posteriores (Freud, (1916) 2004: 272). As fantasias individuais, que agem como fator etiológico da neurose, são geradas por uma "conjunção inconsciente de vivências", provenientes dos diferentes sistemas, consciente e inconsciente, e, se formam, por exemplo, a partir da combinação de fragmentos de cenas visuais ou restos de palavra que foram ouvidos, que por sua vez são reconfigurados (Freud, (1916) 2004: 293).

Para Freud há fantasias que sempre foram inconscientes, formadas no inconsciente, bem como fantasias conscientes que depois se tornaram inconscientes pela repressão, e que ao se tornarem inconscientes, "prontamente poderiam se tornar patogênicas, vale dizer, expressas em sintomas e ataques [histéricos]" (Freud, (1908) 2004: 142). Tais fantasias seriam estágios psíquicos 
prévios ao surgimento do sintoma, ainda que o nexo a ser estabelecido entre eles seja bastante complexo e dependa, nas palavras de Freud, "das dificuldades com as quais se deparam as necessidades das fantasias inconscientes em encontrar expressão" (Freud, (1908) 2004: 144). Isso quer dizer que o sintoma expressa o compromisso entre diferentes forças pulsionais, dentre elas, necessariamente, pulsões sexuais como componentes do material da fantasia, e, forças pulsionais que se opõem a essas pulsões sexuais, ou seja, forças que reprimem a libido, provenientes da realidade ou dos sistemas ligados a ela.

Essas fantasias compõem um dos fatores constitutivos da neurose, enquanto disposição herdada (Anlage) ou inata à criança. No entanto, pode-se dizer ainda que elas são elementos constitutivos de uma sexualidade primitiva do gênero humano (pré-histórica). Na equação da etiologia da neurose é possível ver a relação entre esses elementos que não seria outra coisa que o resultado da soma de fatores internos e externos:

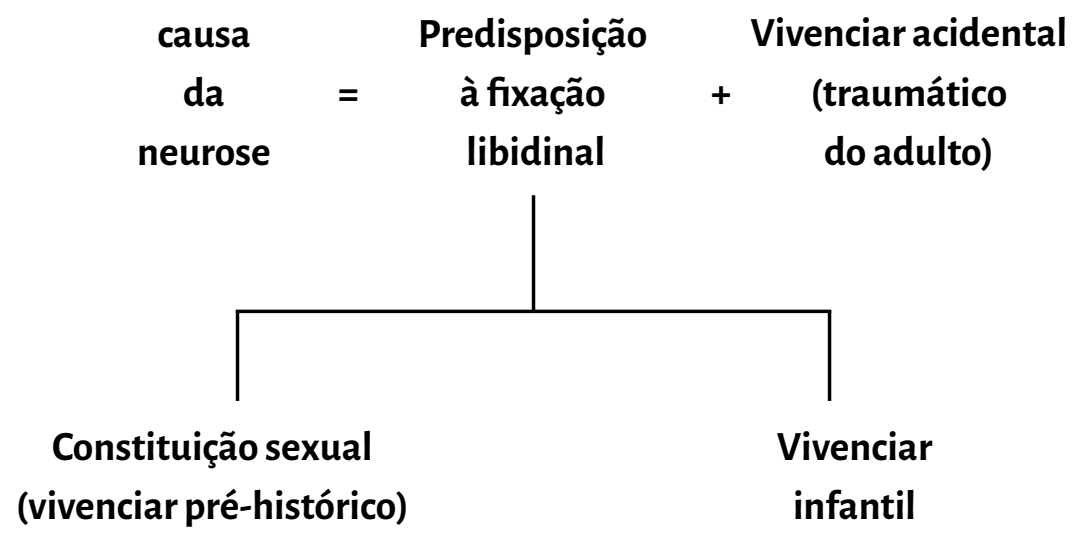

Na equação acima, tem-se que a neurose é causada pela soma da predisposição à fixação libidinal a uma vivência acidental (traumática) do adulto. A libido encontra-se fixada quando não avança completamente no curso de seu desenvolvimento, isto é, uma parcela da aspiração sexual permanece em estágios anteriores do desenvolvimento ainda que outras tenham alcançado a sua meta última (descarga da energia sexual). A predisposição à fixação seria, por sua vez, o fator interno à etiologia da neurose e o trauma acidental, ou a frustração, seria o fator externo (Freud, (1917) 2004: 315). É pela soma desses fatores que se tem o desencadeamento da neurose, pois cada fator é influenciado pelo outro e nenhum deles, isoladamente, pode ser a causa exclusiva da neurose, por isso formam uma série complementar (Freud, 1917 (2004): 316).

Portanto, se temos, por um lado uma série que se complementa como condição para formar o sintoma neurótico, por outro, temos outra série complemen- 
tar como base da predisposição à fixação libidinal, composta pela disposição herdada e pela vivência infantil. Essa outra série, que determina a fixação da libido, apresenta como fator interno a constituição sexual e como fator externo a vivência acidental infantil. A constituição sexual é apresentada como vivenciar pré-histórico, ou dito de outra maneira, como um fator externo que, ao ter sido vivenciado pela espécie, foi posteriormente interiorizado e na atualidade se manifesta individualmente, como parte integrante de uma predisposição (Disposition) do próprio aparelho psíquico.

Não teríamos assim, outro modo de pensar a regra senão como pertencente a todos os seres humanos desde os primórdios? Isto é, não seria essa equação da etiologia da neurose, outro modo de representar a precipitação da cultura, pelas vivências infantis e do adulto sobre uma predisposição constitucional, ou os esquemas mentais vazios e abertos, ainda que esses sejam pensados como historicamente transmitidos?

Freud, num de seus últimos textos, Análise terminável e interminável (1939), insiste quanto à transmissão e herança da cultura:

As particularidades psicológicas de famílias, de raças e de nações, incluindo uma conduta frente à análise, não admitem nenhuma outra explicação, mais ainda: a experiência ana lítica nos tem imposto a conviç̧ão de que, juntamente com certos conteúdos psíquicos, como o simbolismo, não possuem outra fonte que a transferência herdada. Diversas indagações da psicologia dos povos nos sugerem ainda, pressupor na herança arcaica outros precipitados, igualmente especializados, do desenvolvimento do início da humanidade (Freud, (1939) 2004: 242).

Para Lévi-Strauss, a herança do patrimônio constitutivo do ser humano que é histórica não poderia ser pensada como uma transmissão que transcenderia a própria história, isto é, um patrimônio que se encontra na espécie e reapareceria em cada indivíduo:

O fracasso de Totem e tabu, longe de ser inerente ao desenho proposto pelo seu autor, se deve à apresentação de mais uma hesitação que impedem de prevalecer, até o fim, as consequências implicadas em suas premissas. Deveríamos ver que os fenômenos que implicam a estrutura mais fundamental do espírito humano não poderiam aparecer de uma só vez: eles se repetem por inteiro no seio de cada consciência; e a explicação em que se apresenta pertence a uma ordem que transcende a sucessão histórica e as correlações do presente. A ontogênese não reproduz a filogênese, ou o contrário (Lévi-Strauss, (1949) 1967: 563).

A crítica levistraussiana se dirige a uma incoerência de Freud em não admitir e, 
portanto, não tratar a hipótese do assassinato do pai da horda como um mito que se repete e norteia uma cultura em especial. Para o etnólogo, "os fenômenos que implicam a estrutura mais fundamental do espírito humano" fazem parte da cultura na qual o indivíduo está inserido e não podem aparecer de uma única vez, porque a estrutura se compõe e se cristaliza ao longo do tempo e de acordo com uma gama de eventos possíveis (Lévi-Strauss, (1949) 1967: 562).

Além disso, para Lévi-Strauss, Freud só consegue explicar algo a partir do momento em que o passado da espécie se une em cada instante "ao drama multiplicado de cada pensamento individual" (Lévi-Strauss, 1949: 563). Segundo o etnólogo, em Totem e tabu, Freud insiste num passado histórico como modo de justificar a dimensão dada à angústia que o neurótico obsessivo carrega consigo e que, na verdade, não lhe pertence desde seu nascimento, é uma angústia que o transcende.

No entanto, ao nos referirmos às representações e fantasias primitivas, essas não são simplesmente reatualizadas em sua forma bruta, ao contrário, elas ganham outra configuração à medida que se inserem, pelas vias complementares, individualmente. Ou seja, passado e presente não se unem simplesmente, mas ganham nova configuração a cada momento.

Da mesma maneira, podemos pensar a transmissão do mito para a psicanálise. Ela não ocorre oralmente, mas sim por uma via inconsciente, por uma via do corpo, encarnado na fantasia.

Lévi-Strauss, todavia, rejeita a hipótese de que um fato inaugural a originar uma regra universal para todas as culturas. Para a antropologia estrutural, vimos brevemente que a criança carrega consigo estruturas mentais como um fundo comum e indiferenciado, já esboçado ao nascer. Elas seriam três:

Primeira: A exigência da regra como Regra; segunda: a noção de reciprocidade considerada como a forma mais imediata sob a qual pode ser integrada uma oposição entre o eu e o outro; e terceira, a característica sintética da dádiva, quer dizer, o fato de que a transferência consentida de um valor, de um indivíduo a outro, os transforma em parceiros, agregando assim uma qualidade nova ao valor transferido (Lévi-Strauss, (1949) 1967: 98).

Essas estruturas mentais, fundamentais, seriam um fundo comum e indiferenciado que cada criança traz esboçado consigo ao nascer. E, é a partir de tais estruturas que a criança define suas relações com o mundo e com o outro. Essas estruturas compõem de maneira embrionária, a soma de todas as possibilidades de determinada cultura em seu respectivo período e a particularidade das relações a serem estabelecidas dependeria de uma escolha feita pela criança. Essa escolha é mediada e determinada pela sua organização social: "uma escoIha que o grupo impõe e perpetua". O pensamento do adulto se caracterizaria 
então pelas escolhas que fizera e que rejeitara conforme as exigências do grupo e se diferenciaria do pensamento infantil, pela cristalização ocorrida na experiência individual (Lévi-Strauss, (1949)1967: 108). Temos assim que partir dessas estruturas o indivíduo define suas relações com o mundo. Contudo, a comparação nos instiga a algumas perguntas: a regra universal da proibição do incesto, que marca a passagem da natureza para a cultura, não seria justamente marcada por sua universalidade, isto é, uma regra que vale para todas as culturas e que contradiria toda a especificidade de culturas em particular? Além disso não seria ela, tanto quanto a hipótese da horda primitiva, uma conjectura teórica?

Lévi-Strauss considera, a partir de O pensamento selvagem (1962) uma relação entre história e estrutura que se torna mais complexa. Segundo Keck, "a estrutura é deformada pela história, mas ela é capaz de absorver a história pelo efeito de um feedback que reconstitui as oposições pertinentes" (Keck, 2011: 121). Ou seja, o etnólogo introduz uma noção nova, a de transformação, em que há uma "conservação das oposições lógicas constitutivas de uma estrutura para além das evoluções históricas e geográficas" (Keck, 2011: 121). Desse modo haveria sempre uma oposição lógica que não é transmitida como conteúdo, mas como uma oposição que se mantém no espaço e no tempo enquanto estrutura e que é reativada pela própria história. Há, portanto, uma composição em que forma e conteúdo se opõem e se complementam.

Dessa maneira a concepção freudiana de que há uma recapitulação da filogênese pela via ontogenética que já era impensável, torna-se ainda mais absurda, pois invalidaria definitivamente a interdição do incesto como pensada por Lévi-Strauss. A interdição não poderia fazer, ela mesma, o papel da história, pois ela compõe a estrutura, o que quer dizer que ela poderia apenas ser reativada pela própria história. No entanto, afirmar que a estrutura é deformada pela história implicaria também mudar a condição da interdição do incesto e, portanto, da oposição entre natureza e cultura.

\section{CONSIDERAÇÕES FINAIS: OPOSIÇÕES ENTRE NATUREZA E CULTURA}

Conforme nossa argumentação, em 1949 a proibição do incesto é para Lévi-Strauss uma regra universal, um "processo pelo qual a natureza ultrapassa-se a si mesma" e forma uma estrutura de novo tipo. Lévi-Strauss, 1967 (1949): 29) Essa seria mais complexa e viria a se superpor para se integrar às formas de estruturas mais simples da própria vida animal. Isto é, configura-se assim um processo em que a natureza como um todo, ou uma unidade, é ultrapassada em oposição à cultura. Já em O totemismo hoje, Lévi-Strauss parece anunciar uma relativização da unidade natural, como irá fazê-lo em O pensamento selvagem. No primeiro texto, o etnólogo chama a atenção do leitor para a posição de Rousseau que mesmo 
sem ter o conhecimento de uma etnologia de campo aborda o problema da oposição entre natureza e cultura de modo original, pois define a condição natural do homem "em meio ao único estado psíquico cujo conteúdo é afetivo e intelectual, indissociavelmente" (Lévi-Strauss, 1962b: 148). Nesse sentido, Lévi-Strauss nos diz que a tomada de consciência é suficiente para converter-se de um plano ao outro: "a identificação com o outro, uma dualidade de termos corresponde a uma dualidade do aspecto" (Lévi-Strauss, 1962b: 149). Isso porque primitivamente, o homem sente-se idêntico aos seus semelhantes (os animais), o que o torna capaz de se distinguir como eles, os animais, o distinguem, isto é, a diversidade das espécies seria um suporte conceitual da diferenciação das espécies (Idem).

O que observamos a partir da leitura que o etnólogo faz de Rousseau é que desde a identificação tem-se uma noção da diversidade, ou ainda, da diferença entre si e o outro e, portanto, da própria variabilidade da natureza. A natureza não compõe mais uma unidade, portanto, há uma possibilidade de pensar numa natureza humana. A partir de O pensamento selvagem, a natureza já não é mais uma unidade primordial e sim um conjunto de oposições diferenciais, o qual pertence também à cultura. Nas palavras do etnólogo:

As condições naturais não são mais submetidas. Ou ainda, elas não têm mais existência própria, pois elas são em função das técnicas e da população que as definiu e que as deu sentido (...) (Lévi-Strauss, 1962a: 117).

A concepção que os homens fazem da relação entre natureza e cultura ocorre em função da maneira que se modificam suas próprias relações sociais (Lévi-Strauss, 1962a: 144).

Desse modo tanto em As estruturas Elementares quanto em O pensamento selvagem, Lévi-Strauss ao opor natureza e cultura, parece não considerar essa natureza humana, como proposta por Rousseau, ainda que mantenha uma cultura humana no horizonte. Quem muda de estatuto ao longo do tempo é a natureza e sua relação de oposição com a cultura que, por sua vez, só pode ser humana. A natureza deixa de ter um papel de anterioridade à atividade humana. Só podemos atribuir algum papel à primeira a partir da segunda, como podemos ver no caso do bricoleur que é contraposto ao do engenheiro, que se apropria de uma natureza muda e lhe impõe seus projetos. O bricoleur se utiliza de objetos híbridos, metade naturais, metade culturais, resíduos de processos culturais vistos em seu estado natural e os combina de modo a lhes atribuir um novo um significado novo. Segundo Lévi-Strauss:

O bricoleur se dirige sempre a uma coleção de resíduos de obras humanas, isto é, a um subconjunto da cultura. O sábio, [assim como o bricoleur], jamais dia- 
loga diretamente com a natureza pura, mas com certo estado de relação entre a natureza e a cultura, definivel pelo período da história na qual ele vive, a civilização que é a sua e os meios materiais do qual ele dispõe (Lévi-Strauss, 1962a: 34).

Por um lado Lévi-Strauss diz que a natureza passa a existir entremeada à cultura sem Ihe atribuir uma anterioridade. Mas por outro, ela passa a ter o papel do tempo e da história que podem reativar a estrutura da cultura humana. Ora mas não estaria assim atribuindo à natureza uma característica essencialmente humana? E, por sua vez, a cultura humana não o é somente porque se encontra entremeada a uma natureza que lhe é própria; e é natureza, porque assim como os outros animais, é conhecida a partir de uma diversidade?

Ainda que consideremos, seguindo a antropologia estrutural de Lévi-Strauss, o argumento psicanalítico como um erro teórico, a proposição freudiana é justamente de que o parricídio teria originado a cultura, uma vez que esse evento pode ser situado historicamente. É possível indicar que há um processo de identificação, no sentido rousseauísta, dos filhos com o pai. É a partir do assassinato desse último que se tem o conhecimento de algo que pode ser e de algo que não é possivel ser. Ou seja, os filhos mataram o pai porque queriam ocupar seu lugar e obter todas as mulheres do clã, mas não poderiam mais sê-lo, pois o lugar do pai encontrava-se ameaçado uma vez que os filhos poderiam novamente se unir e mais uma vez cometer o assassinato do pai/irmão. Não seria esse então, um ato de cultura humana enraizado na própria natureza humana? Teríamos assim um homem natural diverso de outro homem natural que ao se diversificar encontra-se inserido no processo da cultura. O significa dizer que há, portanto, uma ancoragem da própria cultura na diversidade da natureza.

Janaina Namba é professora pelo Departamento de Filosofia da Universidade Federal de São Carlos (DFil- UFSCar). Antes disso realizou pós-doutorado também pelo DFil-UFSCar, nas áreas de Psicanálise e Antropologia. Tem experiência e trabalha atualmente com Filosofia da Psicanálise.

\section{REFERÊNCIAS BIBLIOGRÁFICAS}

DURIEUX, Marie Claire; NAYROU, Félicie e PARAT, Hélène 2006 Interdit et tabou. Paris, PUF. 
FRAZER, James George

1922 Les Origines de la famille e du clan. Trad. Comtesse Jean de Pange. Paris, Paul Ceuthner.

FREUD, Sigmund

(1937-1939) 2004 Moisés y la religión monoteísta. Esquema del psicoanálisisy otras obras (1937-1939), v. XXIII. Trad. José L. Etcheverry. Buenos Aires, AE. (1906-1908) $2004 \quad$ El delirio y los sueños en la Cradiva de W. Jensen y otras obras (1906-1908), v. IX. Trad. José L. Etcheverry. Buenos Aires, AE.

(1893-1899) $2004 \quad$ Primeras publicaciones psicoanalíticas (18931899), v. III. Trad. José L. Etcheverry. Buenos Aires, AE.

(1886-1899) $2004 \quad$ Publicaciones prepsicoanalíticas y manuscritos inéditos en vida de Freud (1886-1899), v. I. Trad. José L. Etcheverry. Buenos Aires, AE.

(1916-1917) $2004 \quad$ Conferencias de introducción al psicoanálisis (19161917), v. XVI. Trad. José L. Etcheverry. Buenos Aires, AE.

(1913-1914) 2004 Tótem y tabú y otras obras (1913-1914), v.

XIII. Trad. José L. Etcheverry. Buenos Aires, AE.

(1913) 2013 Totem e tabu. Trad. Paulo C. Souza. São Paulo, Editora Companhia das Letras/Penguin.

KECK, Frédéric

2011 Claude Lévi-Strauss, une introduction. Paris, Pocket.

LEVI-STRAUSS, Claude

(1949) 1967 Les Structures éleméntaires de la parenté.

Berlim/Nova York, Mouton de Cruyter.

1962a La Pensée sauvage. Paris, Plon.

1962b Le Totémisme aujourd'hui. Paris, PUF. 
ABSTRACT

In The Elementary Structures of Kinship (1949), Lévi-Strauss referred to the prohibition of incest as a rule found in all peoples and at all times, that is, a universal rule that marks the transition from nature to culture. Freud in Totem and Taboo (1913), also describes this rule, but as a consequence of an murder act, than would also be originated the culture. The proposal of this text is to reflect on some possible approaches between these two theories that concerns the prohibition of incest.

Recebido em 5 de maio de 2016. Aceito em 27 de junho de 2017.
KEYWORDS

Claude Lévi-Strauss, Sigmund Freud, Prohibition of incest, Oedipus complex, Myth 